\title{
Sobre creo (que) subjetivo (e intensificador) en las sesiones de debate parlamentario $^{1}$
}

\author{
On subjective (and intensifier) I think (that) in parliamentary debate sessions
}

\author{
M. Amparo Soler Bonafont
}

\begin{abstract}
Resumen
El presente artículo realiza un análisis del comportamiento de la forma doxástica creo (que) cuando se trata de un verbo modal de subjetivización, especialmente en su manifestación de la categoría pragmática de intensificación, en el debate parlamentario en España. En este género, la bibliografía precedente ha considerado que con frecuencia el cometido de creo (que) es, efectivamente, intensificador (Fuentes 2010, Brenes 2015, Cuenca 2015), si bien las aproximaciones pragmáticas a este tipo de formas verbales doxásticas, no solo en el ámbito del español (Hennemann 2012; Albelda, Briz, Cestero, Kotwica y Villalba 2014), sino también en el panorama internacional (Lakoff 1972; Hooper 1975; Lysvag 1975; Fraser 1975, 1980; Holmes 1984; Caffi 1999, 2004), las han clasificado generalmente como piezas atenuantes. El objetivo de este trabajo es realizar una descripción de creo (que) en el debate parlamentario español, con un foco especial en el desarrollo de la intensificación. Se ofrece un análisis entre lo cualitativo y lo cuantitativo de la forma verbal doxástica seleccionada, en un corpus de 351888 palabras, en el que se evalúan la incidencia de distintos factores formales, de significado, de imagen y también otros de carácter discursivo, con tal de proporcional una explicación detallada del proceder pragmático de creo (que).
\end{abstract}

Palabras claves: creo (que), verbos doxásticos, intensificación, atenuación, imagen

\begin{abstract}
This paper presents a behavioral analysis of the doxastic form creo (que) as a subjectification modal verb, specifically in its manifestation as a pragmatic intensifier device in a Spanish parliamentary debate. Previous work on creo (que) has suggested that it is indeed an intensifier (Fuentes 2010, Brenes 2015, Cuenca 2015), although many pragmatic approaches to these doxastic verbal forms, not only in the context of Spanish (Hennemann 2012; Albelda, Briz, Cestero, Kotwica y Villalba 2014) but also from other languages (Lakoff 1972; Hooper 1975; Lysvag 1975; Fraser 1975, 1980; Holmes 1984; Caffi 1999, 2004), have classified creo (que) as a marker of attenuation. The goal of this investigation is to show a comprehensive description of the behavior of creo (que) in a Spanish parliamentary debate, especially focused on its development as a an intensifier. Using mixed qualitative and quantitative methods, the preselected doxastic form creo (que) is analyzed from a corpus of 351,888 words. Factors considered include formal features, meaning, aspects of face and other discourse features, with the purpose of providing a detailed explanation of the pragmatic procedure of creo (que).
\end{abstract}

Keywords: creo (que), doxastic verbs, intensification, attenuation, face

\footnotetext{
${ }^{1}$ Este artículo ha sido posible gracias al proyecto de $\mathrm{I}+\mathrm{D}$ La atenuación pragmática en su variación genérica: géneros discursivos escritos y orales en el español de España y América (ref. FFI2016-75249-P, MINECO), y a la Ayuda para contratos predoctorales para la formación de doctores 2014 (ref. BES-2014-070173, MINECO), de la que la autora es beneficiaria.
} 
M. Amparo Soler Bonafont, Universitat de València, M.Amparo.Soler@,uv.es

Recibido: julio 2018 / Aceptado: octubre 2018

DOI 10.17710/tep.2018.4.1.4solerbonafont

\section{Introducción}

Creo y creo que son dos de las manifestaciones más frecuentes de la forma de primera persona del singular del presente de indicativo del verbo creer, en cuyas lecturas el hablante modaliza el discurso con de la impresión de su actitud sobre lo dicho. De acuerdo con la bibliografía internacional que ha definido el comportamiento pragmático de este tipo de formas verbales doxásticas (Benveniste 1958, Nuyts 2001²), estas manifestaciones de creer se caracterizan por ser subjetivizadoras, si bien no ha sido esta la característica que más fervientemente se les ha atribuido, sino la de ser tácticas de atenuación (Lakoff 1972; Hooper 1975; Lysvåg1975; Fraser 1975, 1980; Holmes 1984; Caffi 1999, 2004).

Algunos estudios con corpus realizados sobre distintos tipos de textos -desde la conversación coloquial, que ha sido el género más atendido hasta la fecha (BlancheBenveniste 1989; Andersen 1997; Wichmann 2001; Mindt 2003; Schneider 1999, 2007; Kaltenböck 2010; Mullan 2010; Travis y Torres Cacoullos 2012, 2014), hasta otro tipo de discursos como las entrevistas informales (Miyajima 2000) o la prensa escrita (Hennemann 2012, Soler 2016) - dan la razón a los padres de la pragmática y observan que el valor de atenuación es el más frecuente en los usos modalizadores de creo (que). No obstante, en otros géneros más polémicos como los que engloba el discurso político (desde las entrevistas políticas a las comisiones, los discursos, los debates políticos televisivos o los parlamentarios, por nombrar algunos entre los que más se ha estudiado creo (que)), se observa que la forma verbal objeto de estudio no solo expresa valores de atenuación, sino que puede comportarse, incluso con mayor frecuencia, como mecanismo intensificador (Fuentes Rodríguez 2010, 2013; Brenes Peña 2015; Cuenca 2015).

El objetivo de este artículo es analizar un corpus de debate parlamentario en España, con el fin de determinar qué es lo que ocurre en las manifestaciones de creo (que) cuando se comporta allí como subjetivizadoras. En este sentido, se propone comprobar si, de acuerdo con la bibliografía que ha atendido a este tipo de discurso interaccional formal,

\footnotetext{
${ }^{2}$ Estos autores han realizado distintos trabajos con un foco de atención en je crois, je suppose, I think, etc.
} 
la categoría pragmática que principalmente expresa creo (que) en el debate parlamentario es la de intensificación -lo que, en principio, sería contradictorio con las propuestas de los tratados pragmáticos que engloban de manera casi incontestable esta forma verbal entre las principales tácticas de atenuación-, a la vez que evaluar qué motiva su aparición y de qué tipo es, de acuerdo con la propuesta de funciones intensificadoras de Briz (2017).

Se ha realizado un estudio de creo (que) en un corpus de debate parlamentario de 351 888 palabras, compuesto por diferentes sesiones plenarias y de diputación permanente del Congreso de los Diputados del Gobierno de España y otras sesiones plenarias de Les Corts Valencianes de la Generalitat Valenciana, entre los años 2014 y 2017.

En lo que sigue se realiza un breve recorrido teórico por las investigaciones previas sobre creo (que) y, más concretamente, sobre las centradas en discurso político ( $(2)$, se explica la metodología del estudio (\$ 3 ) y se presentan el análisis y discusión de los datos $(\mathbb{S}$ 4). Finalmente, se recogen las conclusiones $(\$ 5)$ y las referencias consultadas.

\section{Creo (que): una forma verbal de subjetivización}

Creo y creo que son dos de las manifestaciones formales más utilizadas de la forma performativa del verbo doxástico creer, si bien no las únicas de entre la multiplicidad de construcciones con la que esta puede representarse (Buceta 2014). Podemos reconocer distintas expresiones de creo, bien parentéticas, bien integradas junto al transpositor que, como acabamos de ver. Si bien, también existen otros casos en los que creo exige régimen preposicional (creo en), es reflexivo (me lo creo), aparece en expresiones fijadas como la categorizada como locución adverbial ya lo creo, puede ser introductor de un predicativo del complemento directo del verbo (creo importantes estas cosas), combinarse con una forma no personal del verbo regido (creo entender), etc. No obstante, no todas las posibles construcciones de creo se consideran introductoras de la actitud del hablante en lo dicho, sino solo algunas de ellas. Se puede establecer una diferencia entre las que podrían considerarse lecturas proposicionales de creo (creo en, me lo creo, ya lo creo...) y otras no proposicionales o modales (creo, creo que, creo + PVO del OD...). Lo que las distingue es el hecho de que en las segundas se hace explícita la subjetividad del hablante en el discurso (no aportan contenido proposicional, sino que añaden otro tipo de información, de carácter evaluativo o compromiso epistémico), mientras que en las primeras nos encontramos ante lecturas con un mayor grado de composicionalidad: el significado del enunciado puede 
derivarse de creo y la suma de los correspondientes elementos que aparecen en combinación con esta forma verbal.

Los últimos casos, esto es, las lecturas modales de creo -cuando este se manifiesta de manera parentética, cuando rige una cláusula de infinitivo o cuando introduce un predicativo del complemento directo de la cláusula principal- y de creo que, son sobre los que más ríos de tinta han corrido. Estas lecturas, en que creo (que) es subjetivizador, han supuesto un reto para la comunidad científica desde finales del siglo XIX, en que la filosofía del lenguaje les reconoce la gran dificultad de descripción de su comportamiento significativo desde el punto de vista de la semántica formal (Frege 1892, Russell 1918). Lo que ocurre con estas formas subjetivizadoras de creo es que, pese a que sus manifestaciones son en su conjunto modales (introducen la actitud del hablante sobre lo dicho), desde el punto de vista de su significado son altamente polisémicas. Es por ello que estudios de diferente corte -teóricos, exploratorios con corpus, etc.- han tratado de dar una nómina de valores significativos básicos de creo: reportativo y expresivo (Kimball 1975); de creencia y de impresión (Blanche-Benveniste 1989); de creencia, evaluación subjetiva, opinión basada en la probabilidad y opinión pura (Persson 1993); literal, epistémico y argumentativo (Simon-Vandenbergen 2000); de opinión, creencia, blanqueamiento, recuerdo e imaginación (Mindt 2003); de creencia y opinión (González Ruiz 2014, 2015); o de creencia y de duda (Posio 2013), entre otros. Puede observarse que, al menos, dos de los valores apuntados por todos los autores que de uno u otro modo se han acercado al estudio de creo en el panorama internacional, se repiten. Se trata de la lectura débil, epistémica o de duda, por un lado, y la lectura fuerte, deliberativa u opinativa, por otro (Simon-Vandenbergen 2000). En este sentido se orientan los estudios que enfrentan un valor de creencia a otro de opinión, que si bien no son los únicos valores semánticos de creo subjetivo, sí son los más frecuentes y atendidos hasta la fecha.

\subsection{Breve resumen de la adscripción funcional de creo (que) en la bibliografía internacional}

En la manifestación de los dos valores frecuentes de creo - tentativo/deliberativo-, lo que más ha interesado a la comunidad científica desde principios del siglo XX ha sido su adscripción funcional. Desde los tratados de pragmática inaugurales, creo ha sido ejemplificado como táctica de atenuación por excelencia (Lakoff 1972, Hooper 1975, Lysvåg 1975, Fraser 1980, Leech 1980). También así lo consideran estudios monográficos 
posteriores centrados en el análisis del fenómeno de la atenuación (Holmes 1984; Caffi 1999, 2004; Schneider 2010) u otros trabajos con corpus realizados sobre esta u otras formas de primera persona de los verbos doxásticos (Venier 1991; Andersen 1997; Wierzbicka 2006; Mullan 2010; Schneider et al. 2015; Soler 2016, 2018). Lo que faltan es, en muchos casos, estudios más amplios de corpus que avalen las afirmaciones que, con mayor o menor alcance, se han realizado en los estudios previos.

Quienes defienden la atenuación como categoría pragmática preponderante de creo se basan, por un lado, en su carga epistémica débil (la evaluación de la probabilidad que manifiesta en algunos casos) que, apuntan, es la que más frecuentemente se hace explícita en sus usos modales (Nuyts 2001, De Saeger 2007, Fetzer 2014, González Ruiz 2014). Estos autores también destacan la reducción de la fuerza ilocutiva de los actos que creo expresa (Hooper 1975, Holmes 1984, Blanche-Benveniste y Willems 2007). Véase (1):

(1) Diputada Elisa Díaz González (grupo parlamentario Popular): [...] Miren, vaya papelón. Si yo lo sé, vaya papelón tiene usted. Creo que en la lista esa de muchos ayuntamientos -no he nombrado a todos-, de muchos ayuntamientos que han alegado al Pativel, no sé si lo he citado, Alfaz del Pi, ¿lo he citado? Creo que sí, ¿no? Menudo papelón tiene usted, señor Briet, que Alfaz del Pi también ha alegado contra el Pativel, sí [...]

Sessió Plenària, Les Corts Valencianes, 9/3/2017

Obsérvese cómo, en las dos ocurrencias de creo que del ejemplo, la diputada expresa un bajo grado de seguridad sobre la realidad factual que describe: ella presenta como una posibilidad o duda el hecho de haber nombrado a la población de Alfaz del Pi entre las localidades relatadas. En su descripción de lo expuesto, opta por utilizar un verbo epistémico débil para suavizar la aserción, bien porque acaba de contradecirse -si efectivamente no ha nombrado aquella población-, bien porque no puede hacer más fuertemente asertiva una descripción de lo que no puede recordar con claridad. Este valor modal de creo reduce el efecto negativo de lo dicho y suaviza, a la vez, los posibles efectos que aquello tenga en la o las imágenes de los participantes de la interacción.

Existen otros usos modales de creo, no obstante, en los que este no se reconocen tanto usos epistémicos, sino otros más bien argumentativos. Son ejemplos como el de (2): 
(2) Diputado Alberto Garzón Espinosa (grupo parlamentario Izquierda Unida): Sí, señor Montoro, en cualquier caso no ha respondido a la pregunta concreta, y creo que usted es plenamente consciente de que esta reforma fiscal es absolutamente regresiva porque afecta desigualmente, muy desigualmente, según la clase social [...] Pleno y Diputación Permanente, Congreso de los Diputados, 25/6/2014

En este fragmento, el diputado de Izquierda Unida, Alberto Garzón, utiliza creo que para introducir su punto de vista -que es compartido por todo su grupo parlamentario- sobre lo dicho. Ahora no expresa inseguridad para con la aserción, como hacía la diputada de (1), sino que expone que su interlocutor (el exministro de Hacienda y Administraciones Públicas, Cristóbal Montoro) debe ser consciente de que la reforma fiscal que propone no es beneficiosa para la ciudadanía española, pues genera desigualdad entre las clases sociales. Ahora el hablante no deja abierta la posibilidad de que lo dicho sea o no cierto, no duda. Aquí no se hace una descripción más o menos fiel de una realidad, sino una evaluación subjetiva sobre un hecho. Esto es, nos encontramos ante un juicio o valoración, y no ante una estimación del grado de seguridad con que puede radiografiarse un estado de cosas del mundo. La bibliografía se pregunta hasta qué punto estos usos opinativos de creo (que) pueden expresar o no atenuación, pues su naturaleza argumentativa los convierte en recursos más apropiados para vehicular la intensificación.

Si bien no todas las manifestaciones opinativas de creo (que) son intensificadoras, existen razones para pensar que la introducción de los puntos de vista personales es más afín a manifestar este tipo de funciones pragmáticas. Quienes defienden estos usos intensificadores se basan en el alto grado de responsabilidad del hablante en este tipo de aserciones, en la mayor confrontación a la que se ven abocadas las opiniones en este tipo de discurso y que exige una defensa más exacerbada de los puntos de vista propios, y/o en el énfasis aparejado a su irrupción en un género como pueda ser el debate parlamentario (Fuentes Rodríguez 2010, Brenes Peña 2015, Cuenca 2015).

\subsection{Una aproximación genérica a creo (que): la manifestación de sus categorías pragmáticas en el debate parlamentario}

$\mathrm{Si}$, como se ha visto, son varias las posibilidades significativas y funcionales de creo (que) en distintos contextos sobre los que se han realizado algunos estudios, también son múltiples las posibilidades comportamentales que esta forma ofrece en el discurso político. En este 
ámbito de uso político es en uno de los que más atención ha recibido creo (que), tras la conversación coloquial, bien porque potencia la aparición de múltiples manifestaciones, bien porque los géneros que engloba propician algunas lecturas semánticas mucho más específicas que en otro tipo de textos. En el discurso político, se han analizado las formas verbales doxásticas en diferentes géneros: comisiones (Berlin 2008, 2011), conferencias y discursos políticos ${ }^{3}$ (Fraser 2010, Rabab'ah y Abu Rumman 2015), entrevistas políticas (Fetzer y Johansson 2010, Šandová 2015), comentarios políticos en prensa (Pano 2017), debates políticos televisivos (Johansson 2008) y debates parlamentarios (Fuentes Rodríguez 2010, 2015, 2016; Brenes Peña 2015) ${ }^{4}$. En muchas de estas investigaciones se focaliza la categoría de atenuación de creo (que), si bien se reconoce su convivencia con la de intensificación. En el caso concreto de los debates parlamentarios, se apunta que esta última es su categoría pragmática principal.

De acuerdo con De Cock (2014), el debate parlamentario es un género interactivo oral, altamente preparado y planificado de manera previa a su locución y, por tanto, dirigido, lo que le confiere muchas de las características propias de lo escrito. La fuente de lo dicho y el destinatario no son únicamente el hablante y el receptor efectivos del acto comunicativo concreto, sino una colectividad, y la distribución de sus turnos viene predeterminada. Los tipos de actos de habla que allá predominan son declarativos y, tanto por ello como por la naturaleza (polémica) de los contenidos expuestos, los verbos enunciados suelen aparecer en primera persona. Estas características transforman el debate en un campo propicio para el estudio del comportamiento de creo (que), y donde resulta esperable una alta frecuencia de aparición. Asimismo, la idiosincrasia conflictiva del género facilita la aparición del énfasis en la presentación de lo dicho o la necesidad de disponer los propios argumentos para vencer y no tanto para convencer (Fuentes Rodríguez 2010), lo que puede propiciar que surja efectivamente la intensificación, pero por razones ajenas a la semántica básica de creo ${ }^{5}$. Es necesario, no obstante, identificar qué criterios permiten el

\footnotetext{
3 Son intervenciones monológicas de representantes políticos en instituciones internacionales (ej. Abdullah II ante el Parlamento Europeo o la Asamblea General de la ONU, vid. Rabab'ah y Abu Rumman 2015).

4 Algunos de estos trabajos se han realizado sobre el inglés (Berlin 2008, 2011; Johansson 2008; Fetzer y Johansson 2010; Fraser 2010; Rabab’ah y Abu Rumman 2015; Šandová 2015). Otros son estudios de discurso político en español (Fuentes Rodríguez 2010, 2015, 2016; Brenes Peña 2015; Pano 2017).

5 Como se expone en $\int 2$, la bibliografía sobre las formas performativas de los verbos doxásticos suele establecer una correspondencia directa entre los valores semánticos de estas -tentativo/deliberativo- y su categoría pragmática -atenuación/intensificación, respectivamente-. Ahora bien, ni esta relación es directa ni debería responder única y exclusivamente a cuestiones de significado y/o de género. No obstante, sí debe tenerse en cuenta el factor semántico en la determinación de las funciones discursivas.
} 
desarrollo de sus funciones y, específicamente, las de intensificación, a partir de estudios de corpus que avalen su comportamiento ${ }^{6}$.

\section{Metodología del análisis}

El artículo analiza las ocurrencias de creo (que) en el debate parlamentario español entre 2014 y 2017. Se opta por este género con el cometido de observar qué es lo que ocurre en el caso del español, dado que es uno de los tipos de discurso más atendidos también en materia de formas verbales doxásticas en otras lenguas. Se comprueba, así, si las afirmaciones bibliográficas se corresponden con la realidad de la expresión lingüística.

El corpus seleccionado es de 351888 palabras, repartidas entre sesiones plenarias y de diputación permanente del Congreso de los Diputados, del Gobierno de España, y otras sesiones plenarias de Les Corts Valencianes, de la Generalitat Valenciana. Las sesiones se han elegido teniendo en cuenta los recursos disponibles en las páginas electrónicas del congreso nacional y del congreso autonómico valenciano ${ }^{7}$. En el primero se han contabilizado todas las palabras de las sesiones; en el segundo, únicamente las palabras en español ${ }^{8}$. Las sesiones seleccionadas de una y otra cámara se reparten de manera equitativa en cuanto al número de palabras, si bien aleatoriamente en cuanto a los años y número de sesiones de cada uno de ellas. La Tabla 1 resume las sesiones analizadas:

\section{Tabla 1}

Distribución de las sesiones plenarias y de diputación permanente analizadas

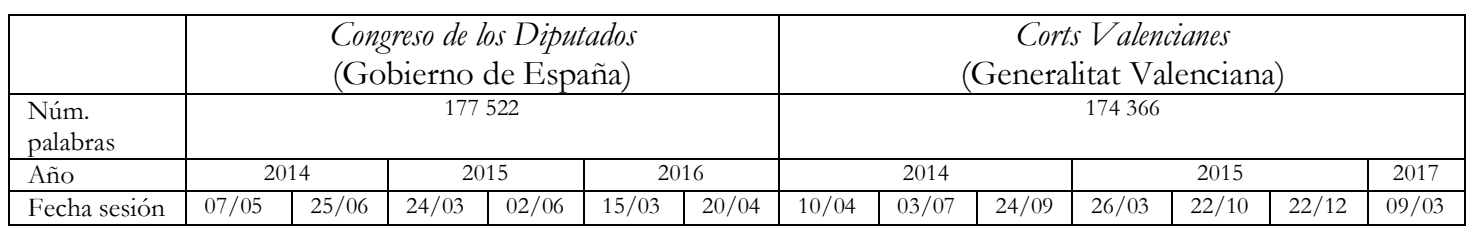

En las 13 sesiones parlamentarias analizadas se han aislado las ocurrencias de creo (que), las dos construcciones con valor modal subjetivo que pueden presentar funciones pragmáticas

\footnotetext{
${ }^{6}$ Estos trabajos son escasos, a excepción de algunos de reciente publicación (Brenes Peña 2015, Cuenca 2015, Fuentes Rodríguez 2016).

7 Tanto la página electrónica del Congreso de los Diputados como la de Les Corts V alencianes (vid. \6) tienen a disposición del ciudadano los diarios oficiales de sesiones transcritas y en formato pdf.

${ }^{8}$ Se han tomado dos corpus de base comparables (con un número de palabras proporcional en ambos), si bien se ha adaptado el material lingüístico, para su contraste. Se prescindido de las partes en catalán en Les Corts V alencianes -que presenta las dos lenguas, por la cooficialidad del catalán y el español en su contexto geográfico-, ya que no son objeto de nuestro estudio.
} 
distintas y se han excluido otras manifestaciones de la forma verbal que presentan lecturas proposicionales (creo en, me (lo) creo, ya lo creo, etc.). Los 295 casos de creo (que) de este tipo obtenidos se han analizado a la luz de los siguientes aspectos:

(a) Primeramente, se han clasificado los casos modales de creo (que) a partir de su construcción formal. Se han reconocido las siguientes posibilidades, previamente anotadas: creo parentético (ej. especialmente -creo- cualificado), creo parentético con verbo regido en infinitivo (ej. creo recordar), creo integrado con transpositor que (ej. creo que es importante) y creo integrado con predicativo del objeto directo del verbo (ej. una ley que creo injusta).

Para la determinación de las posibilidades formales nos basamos en los acercamientos cognitivos que las describen desde un enfoque construccionista (Jaszczolt 1997; Buceta 2014; Hennemann 2016; Torres-Martínez 2017).

(b) Seguidamente, se ha analizado el valor semántico manifestado en cada una de las ocurrencias del verbo a partir de la propuesta de tres significados básicos: conocimiento, posibilidad y juicio. Se trata de tres valores determinados a partir de la bibliografía sobre el tema y de los análisis de corpus realizados. Si bien la literatura apunta una marcada distinción entre los valores tentativo y deliberativo (recuérdese $\S 2)$, en este trabajo se propone un tercer valor extensional en el que, de igual modo que en el tentativo, nos encontramos ante la descripción de realidades, si bien estas no son comprobables en el momento de la enunciación por tratarse de predicciones o anticipaciones de hechos futuribles (ej. creo que va a pedir el turno). Este valor, al que hemos denominado valor de posibilidad, suele reconocerse a partir de los tiempos verbales de futuro, futuro inmediato o condicional del verbo regido por creo (que). En cuanto a los valores etiquetados como conocimiento y juicio, son las nomenclaturas asignadas a los valores tentativo o epistémico, y deliberativo u opinativo, respectivamente, propuestos por la bibliografía?.

(c) También se ha evaluado la incidencia de la imagen en el contexto interactivo concreto (CIC, Albelda et al. 2014) en el que creo (que) hace su irrupción. Los

\footnotetext{
${ }^{9}$ Hemos tomado los valores previamente anotados en la bibliografía, y hemos propuesto uno nuevo. Los dos tomados de la bibliografía se han renombrado como valores de conocimiento y juicio. En el primero de ellos, el valor de conocimiento, se ha optado por hacer visible en la nomenclatura la naturaleza de lo descrito, pues lo que hace el verbo en la manifestación de este significado es describir una realidad del mundo extralingüístico, unos hechos que pueden ser perceptibles por los sentidos, esto es, se trata de algo que puede ser conocido, aprehendido, por el hablante. En el valor de juicio, la nomenclatura propuesta pone de relieve la evaluación que lleva a cabo el hablante al introducir no una descripción, sino un punto de vista sobre una realidad posible o no. Se trata de una valoración, una evaluación, una opinión, categórica.
} 
estudios más recientes sobre distintos fenómenos pragmáticos defienden una influencia relevante de la implicación de la o las imágenes de los participantes de la interacción en el desarrollo de las funciones de atenuación e intensificación (Albelda 2016, en prensa; Briz 2017). Este análisis toma en consideración estas corrientes de estudio recientes, y otras de carácter sociopragmático (Bravo 2009, Hernández Flores 2013), y trata de evaluar hasta qué punto la involucración de la imagen puede determinar cuándo surge la intensificación en los usos de creo (que) en el debate parlamentario en España. Seguimos, además, las observaciones realizadas por Bolívar (2015), Infante y Flores (2015) y González Sanz (2017) acerca de la imagen y la (des)cortesía en los géneros de discurso político.

(d) Se han observado otros aspectos en el cotexto próximo de creo (que), tales como el fenómeno semántico de la metaforización u otros aspectos pragmáticos como la ironía o el refuerzo de la (des)aprobación de lo dicho, por parte de otros participantes del acto comunicativo, que se explicitan en el discurso a través de distintos recursos para- y supralingüísticos. En el análisis se evaluarán estos factores en su contribución al surgimiento de la intensificación en los usos del verbo objeto de estudio.

(e) Por último, se estudian las funciones pragmáticas de creo (que) en correlación con las variables anteriores. Se analizan los fenómenos de atenuación e intensificación, con especial atención a este último, y si existen otras posibilidades funcionales en el uso de la forma verbal (ej. marcación formulativa, de acuerdo con Fuentes Rodríguez 2010 y Mullan 2010). Por un lado, la atenuación se interpreta como (1) mecanismo para la reducción de la fuerza ilocutiva de los actos de habla, así como (2) fenómeno que implica las imágenes de los interlocutores (Albelda 2016). Por otro, la intensificación, que se analiza en mayor profundidad en este artículo, se entiende como la categoría pragmática a través de la cual se maximiza lo dicho, a partir de los supuestos básicos de escalaridad y evalución (Albelda 2007). En esta categoría se ha valorado la aplicabilidad de las funciones el reconocimiento de la maximización de lo dicho, a saber, intensificación auto-reafirmativa, aloreafirmativa y contra-reafirmativa. En ellas adquieren un papel relevante las actividades de imagen, esto es, las acciones lingüísticas que afectan a la presentación social de los participantes en el acto comunicativo y que, en el caso del debate 
parlamentario, pueden ser ampliadas a las de todo un grupo parlamentario o el conjunto de la población receptora (Hernández Flores 2013).

El análisis es cualitativo, pues se propone extraer generalidades sobre las condiciones co- y contextuales que favorecen la intensificación en creo (que) en el debate parlamentario español, si bien se apoya en datos cuantitativos que avalan la validez de las conclusiones.

\section{Análisis y discusión de los datos}

El corpus proporciona 295 casos de creo (que) en el total de las 13 sesiones parlamentarias, conformadas por 351888 palabras. Su frecuencia relativa de aparición respecto al número total de palabras analizadas $\left(f_{i}=0,00083\right)$ es semejante a la observada en otros corpus de interacción oral (vid. Soler (2018) para la conversación coloquial: $\mathrm{f}_{\mathrm{i}}=0,00098$ ). Este dato demuestra que los valores modales de creo (que) son casi equitativos en lo que a frecuencia de aparición se refiere en distintos géneros interactivos orales en España. Ahora bien, cabrá evaluar otras cuestiones, como las formas bajo las que se representa, los significados que desarrolla y las afectaciones de las imagen de los participantes y/o terceros, tanto como como elementos de otra naturaleza (ej. factores paralingǘsticos), que inciden en cada uno de sus usos para determinar qué es lo que ocurre en el debate parlamentario y, más específicamente, en su proceder pragmático.

\subsection{Manifestaciones formales de creo (que)}

Las sesiones de debate parlamentario proporcionan distintas construcciones formales de creo (que). Los 295 casos se reparten entre formas parentéticas $\left(n_{i}=13 ; 4,41 \%\right.$ ) e integradas $\left(\mathrm{n}_{\mathrm{i}}=282 ; 95,59 \%\right)$. La Tabla 2 recoge sus frecuencias de aparición:

\section{Tabla 2.}

Construcciones de creo (que) en el corpus de análisis

\begin{tabular}{|c|c|c|c|c|}
\hline & & Construcción & $n_{i}$ & $\%$ \\
\hline \multirow{3}{*}{$\begin{array}{c}\text { creo } \\
\text { (parentético) }\end{array}$} & \multirow[t]{3}{*}{ creo } & creo $+\varnothing$ & 10 & 3,39 \\
\hline & & creo + infinitivo & 2 & 0,68 \\
\hline & & no + creo & 1 & 0,34 \\
\hline \multirow{7}{*}{$\begin{array}{c}\text { creo } \\
\text { (integrado) }\end{array}$} & \multirow{7}{*}{ creo que $+\ldots$} & creo que $+\mathrm{X}$ & 249 & 84,41 \\
\hline & & creo que + sí $+\varnothing$ & 7 & 2,37 \\
\hline & & creo que + también & 1 & 0,34 \\
\hline & & creo que + no $+\varnothing$ & 1 & 0,34 \\
\hline & & creo que + no $+X$ & 6 & 2,03 \\
\hline & & creo que + tampoco & 1 & 0,34 \\
\hline & & sí que + creo que & 2 & 0,68 \\
\hline
\end{tabular}




\begin{tabular}{|l|l|l|c|c|}
\hline & también + creo que & 1 & 0,34 \\
\cline { 3 - 5 } & no + creo que + (verbo modo subj.) & 12 & 4,06 \\
\cline { 3 - 5 } & tampoco + creo que + (verbo modo subj.) & 1 & 0,34 \\
\cline { 2 - 5 } & creo + PVO & creo + PVO (del OD) & 1 & 0,34 \\
\hline
\end{tabular}

Como puede observarse en la Tabla 2, las construcciones de la forma verbal estudiada se dividen entre las parentéticas y las integradas. Estas últimas presentan, además, dos posibilidades combinatorias, con o sin transpositor (que/Ø). Algunas de ellas pueden reagruparse en función de algunas observaciones, pues puede verse, por ejemplo, que las afirmaciones o las negaciones, tanto previas o posteriores a la forma verbal integrada -esto es, tanto de la forma verbal regente como de la regida, o la afirmación o negación únicas cuando se entienden estas como enunciado independiente (creo que si $+\varnothing /$ creo que no $+\varnothing)-$ presentan doble posibilidad formal: si/también, no/tampoco. La Tabla 3 recoge estas reagrupaciones realizadas para el manejo de los datos de nuestro análisis:

\section{Tabla 3}

Construcciones de creo (que) reagrupadas en función de algunas observaciones formales

\begin{tabular}{|c|c|c|c|c|}
\hline & & Construcción & $n_{i}$ & $\%$ \\
\hline \multirow{3}{*}{$\begin{array}{c}\text { creo } \\
\text { (parentético) }\end{array}$} & \multirow[t]{3}{*}{ creo } & creo $+\varnothing$ & 10 & 3,39 \\
\hline & & creo + infinitivo & 2 & 0,68 \\
\hline & & no + creo & 1 & 0,34 \\
\hline \multirow{6}{*}{$\begin{array}{c}\text { creo } \\
\text { (integrado) }\end{array}$} & \multirow{5}{*}{ creo que $+\ldots$} & creo que $+\mathrm{X}$ & 249 & 84,41 \\
\hline & & creo que + sí $\varnothing /$ también & 8 & 2,71 \\
\hline & & creo que + no $\varnothing /+$ no $X /$ tampoco & 8 & 2,71 \\
\hline & & sí que/también + creo que & 3 & 1,02 \\
\hline & & $\begin{array}{l}\text { no/tampoco }+ \text { creo que }+ \text { (verbo en modo } \\
\text { subjuntivo) }\end{array}$ & 13 & 4,40 \\
\hline & creo + PVO & creo + PVO (del OD) & 1 & 0,34 \\
\hline
\end{tabular}

Puede observarse el gran predominio de las formas integradas, por tanto, con conjunción: creo que (en el 84,41\% de las ocurrencias en el corpus), cuando estas no sirven a un propósito de afirmación o negación marcadas. En segundo lugar, pero con una frecuencia de aparición mucho menor, encontramos los casos integrados en los que se niega el verbo

\section{Soler Bonafont, M. Amparo (2018). "Sobre creo (que) subjetivo (e intensificador) en las sesiones de debate parlamentario". Textos en Proceso 4(1), pp. 61-92.


regente y se combina este con verbos subordinados en modo subjuntivo (4,40\%). En tercera posición tenemos los casos parentéticos de creo cuando no aparece junto a ellos negación, ni introducen formas no personales de verbos regidos $(3,39 \%$ de los casos).

El resto de construcciones presenta una frecuencia de aparición muy baja. Estas se excluyen del análisis, si bien extraemos algunas conclusiones de aquellas que más aparecen en el corpus, de las que con mayor fiabilidad pueden realizarse generalizaciones.

\subsection{Valores semánticos de creo (que)}

De acuerdo con los valores semánticos propuestos en $\int 3$, podemos confirmar que las distintas manifestaciones formales de creo (que) encontradas en el corpus expresan la totalidad de posibilidades significativas del verbo cuando se comporta como verbo modal subjetivizador: encontramos tanto casos con valor de conocimiento (28 casos; 9,49\%), tradicionalmente reconocido en la bibliografía como valor de tentativo o epistémico, como con valor de juicio (243 casos; 82,37\%), previamente categorizado como valor deliberativo u opinativo. Asimismo, aparece el tercer valor propuesto como posibilidad (en 23 casos, con un $7,80 \%$ de frecuencia). Ahora bien, cabe destacar, a pesar de que se trate de un solo caso $(0,34 \%)$, el reconocimiento de otro valor, que podríamos considerar introductor impreciso, cuya función pragmática de marcación discursiva sí recogen algunos estudios (Fuentes Rodríguez 2010, Mullan 2010). Se trata del siguiente caso:

(3) Diputado Antonio Estañ García (grupo parlamentario Podemos) [...] y no encerrar tuiteros y liberar infantas. (Aplaudiments) Bueno, creo que voy al tema. Estamos acostumbrados a las performances de la señora Díaz. Esto creo que a veces aporta color, pero creo que en el pasado pleno se acabó convirtiendo en algo muy grave, y esperamos que no se repita. [...]

Sessió Plenària, Les Corts Valencianes, 9/3/2017

Se observa en (3) un uso de creo que (en la primera de sus tres manifestaciones) que sirve al hablante para introducir su discurso, tras la pausa realizada en su intervención por motivo de los aplausos de la cámara de diputados. No se reconoce aquí ninguno de los tres valores 
semánticos básicos comentados, sino el de ser un operador que, en todo caso heredado del valor epistémico en ocasiones manifestado por la forma verbal, puede expresar cierto grado de imprecisión, como acabamos de decir, o una inseguridad fingida, más que real, del propio enunciador, que le ayuda a ganar tiempo en su formulación.

Los valores comentados presentan, como se ve, una frecuencia dispar de aparición. En la mayoría de los casos se reconoce el valor de juicio, el que en mayor media se ha aparejado con las funciones de intensificación en el debate parlamentario en la bibliografía precedente, lo que de ser cierto -si existe una correspondencia efectiva o casi directa con la manifestación de dicho fenómeno pragmático- confirmaría lo propuesto en otros estudios: el predominio de la categoría de intensificación en los usos de creo (que) en el debate parlamentario en español. Si bien será necesario evaluar otros factores ( $(4.3)$.

Antes de ello, no obstante, repasamos qué relación se establece entre las formas vistas en $\$ 4.1 y estos valores significativos de creo (que). La Tabla 4 resume esta relación:

\section{Tabla 4}

Relación entre las construcciones formales de creo (que) y los valores semánticos encontrados en el corpus de análisis: frecuencia absoluta y porcentajes

\begin{tabular}{|c|c|c|c|c|c|c|}
\hline & & Construcción & \multicolumn{4}{|c|}{ Valor semántico } \\
\hline & & & conocimiento & posibilidad & juicio & MD \\
\hline \multirow[t]{3}{*}{$\begin{array}{l}\text { creo } \\
\text { (parentético) }\end{array}$} & \multirow[t]{3}{*}{ creo } & creo $+\varnothing$ & $\begin{array}{c}2 \\
(0,68 \%)\end{array}$ & & $8(2,71 \%)$ & \\
\hline & & creo + infinitivo & $\begin{array}{c}2 \\
(0,68 \%)\end{array}$ & & & \\
\hline & & no + creo & & $\begin{array}{c}1 \\
(0,34 \%)\end{array}$ & & \\
\hline \multirow{6}{*}{$\begin{array}{l}\text { creo } \\
\text { (integrado) }\end{array}$} & \multirow{5}{*}{$\begin{array}{l}\text { creo que }+ \\
\ldots\end{array}$} & creo que $+X$ & $\begin{array}{c}22 \\
(7,46 \%)\end{array}$ & $\begin{array}{c}9 \\
(3,05 \%)\end{array}$ & $\begin{array}{c}217 \\
(73,56 \%)\end{array}$ & $\begin{array}{c}1 \\
(0,34 \%)\end{array}$ \\
\hline & & $\begin{array}{l}\text { creo que }+ \text { sí } \\
\varnothing / \text { también }\end{array}$ & $\begin{array}{c}1 \\
(0,34 \%)\end{array}$ & & $7(2,37 \%)$ & \\
\hline & & $\begin{array}{ll}\text { creo que }+ \text { no } \\
\varnothing /+ \\
x / \text { tampoco }\end{array}$ & $\begin{array}{c}1 \\
(0,34 \%)\end{array}$ & $\begin{array}{c}1 \\
(0,34 \%)\end{array}$ & $\begin{array}{c}6 \\
(2,03 \%)\end{array}$ & \\
\hline & & $\begin{array}{l}\text { sí que/también }+ \\
\text { creo que }\end{array}$ & & & $\begin{array}{c}3 \\
(1,02 \%)\end{array}$ & \\
\hline & & $\begin{array}{l}\text { no/tampoco }+ \\
\text { creo que }+ \\
\text { (verbo en modo } \\
\text { subj.) }\end{array}$ & & $\begin{array}{c}12 \\
(4,06 \%)\end{array}$ & $\begin{array}{c}1 \\
(0,34 \%)\end{array}$ & \\
\hline & $\mathrm{creo}+\mathrm{PVO}$ & $\begin{array}{l}\text { creo }+ \text { PVO } \\
(\mathrm{OD})\end{array}$ & & & $\begin{array}{c}1 \\
(0,34 \%)\end{array}$ & \\
\hline \multicolumn{3}{|l|}{ Totales } & $\begin{array}{c}28 \\
(9,49 \%)\end{array}$ & $\begin{array}{c}23 \\
(7,80 \%)\end{array}$ & $\begin{array}{c}243 \\
(82,37 \%)\end{array}$ & $\begin{array}{c}1 \\
(0,34 \%)\end{array}$ \\
\hline
\end{tabular}


En la tabla anterior puede observarse que si bien algunos valores como el de marcador formulativo impreciso se manifiestan a través de una sola construcción formal de creo, los demás son en mayor proporción polimórficos. No obstante, podemos observar algunas tendencias. Por un lado, el valor de conocimiento se suele expresar en el debate parlamentario español con la construcción creo que + verbo $(7,46 \%$ de los casos), si bien se encuentran en segunda posición de frecuencia los casos parentéticos creo $+\varnothing /$ verbo en infinitivo $(0,68+0,68=1,36 \%$ de los casos). Por otro lado, el valor de posibilidad viene representado por la construcción integrada con que (3,05\% de las ocasiones).

Por último, si bien vemos que el valor de juicio es el más polimórfico, también por ser el más frecuente, predomina con construcciones integradas de creo que + verbo $(73,56 \%)$, aunque también es frecuente con formas parentéticas $(2,71 \%)$ y con formas integradas que introducen una afirmación marcada (2,37\%).

Parece, por tanto, que en el debate parlamentario en España lo esperable sea encontrar expresiones formales de creo modal integradas mediante la conjunción que, en la gran mayoría de los casos como introductoras de un valor de juicio, esto es, de un punto de vista personal, en actos asertivos de carácter evaluativo, y en otras, pero en mucho menor proporción, con valor de conocimiento, cuando introducen aserciones que describen de manera imprecisa realidades factuales. Estos dos valores, de juicio y de conocimiento, con la construcción formal comentada (creo que + verbo), son los que presentan un porcentaje de aparición más alto en nuestro corpus, si bien con una notable diferencia entre uno y otro valor: $73,56 \%$ (juicio con creo que + verbo) y 7,46\% (conocimiento con creo que + verbo) (vid. Tabla 4).

\subsection{Actividades de imagen de creo (que) en el debate parlamentario español}

Como se ha comentado en $\ 3$, las actividades de imagen puestas de relieve en las diferentes manifestaciones de creo (que) pueden incidir en la aparición de sus diferentes funciones pragmáticas y, sobre todo, en las de la intensificación. Lo que sí se ha observado es una distribución desigual en las implicaciones de las imágenes de los participantes o entes externos del/al acto comunicativo en los debates parlamentarios. Únicamente en un 0,34 \% de los ejemplos (1 ocurrencia) podemos encontrarnos ante usos de creo en los que no se da ninguna actividad de imagen. Se trata del uso de la forma verbal como marcador formulativo, cuyo cometido es el de ganar tiempo en la elaboración del mensaje. Ejemplificábamos este caso en (3). El resto de ejemplos analizados ponen en juego la 
imagen de alguien, presente o no en el debate. En el 9,49\% de los casos (28 ocurrencias) se ve involucrada la imagen del hablante; en un 5,08\% (15 ocurrencias) se ve efectada la imagen del hablante, pero también de otros, externos a la celebración del acto comunicativo; mientras que en el 85,08 \% de las ocasiones (251 casos) se ven envueltas tanto la imagen del hablante como la del oyente, y también de otros. En cualesquiera de los casos, recuérdese que la imagen del hablante y la del oyente no remiten solo a la persona física presente en el momento de la enunciación (a los diputados que toman la palabra en el congreso), sino que se trata, en el debate parlamentario, de entes colectivos, pues tanto hablante como oyente representan ya no solo el sentir de todo el partido o grupo parlamentario por el cual toman voz, sino que también muchas veces representan al conjunto de votantes o ciudadanos simpatizantes con la ideología de aquellos (De Cock 2014). Veamos con mayor detalle cada uno de estos casos.

En la primera de las situaciones comentada (que se da en el 9,49\% de los casos), aducimos que es únicamente la imagen del hablante, entendiendo este de manera colectiva, la que se pone en juego. Se trata de casos en los que se valoriza la propuesta del yo enunciador. Fijémonos en (4):

(4) Expresidente del Gobierno Mariano Rajoy Brey (grupo parlamentario Popular): [...] Creo que el gran objetivo político de esta legislatura era superar la crisis económica, hemos evitado un rescate, hemos evitado la quiebra de nuestro país, hemos superado una crisis de deuda soberana, una crisis financiera y el gran objetivo ahora es crecer y crear empleo $[\ldots]$

Pleno y Diputación Permanente, Congreso de los Diputados, 7/5/2014

En este uso de creo que, que encabeza la cláusula suscrita por el expresidente del gobierno español, se observa que el juicio o valoración propuesta, el punto de vista defendido por Rajoy: que el objetivo de su legislatura, que era superar una grave crisis económica, se ha cumplido a través de las diferentes acciones que enumera como llevadas a cabo por su gobierno. Vemos que aquí que, más que atacar o poner en juego la imagen de otros -si bien puede hacerlo o se prepara para hacerlo de manera indirecta-, lo que hace el hablante es poner de relieve su propia imagen, revalorizándola y reafirmando su propio punto de vista, a través de una enumeración de los objetivos que se presuponen cumplidos por el grupo parlamentario durante su etapa de gobierno, y de la repetición marcada de los propósitos, 
que en un caso se llevaron a cabo, en otro, están por darse. Se trata de un refuerzo de la imagen del yo. Esta observación de la tendencia, en las interacciones orales en español, a la centralidad y valoración de la imagen del yo ha sido apuntada en otro tipo de trabajos (Douglas, Soler y Vuoto 2018).

En otros casos (5,08\%), podemos observar cómo a la implicación de la imagen del yo se le suma la de otros, terceros, externos al acto comunicativo. Veamos en el ejemplo (5) esta segunda de las tres situaciones comentadas:

(5) Diputado José Enrique Muñoz Lladró (grupo parlamentario Socialista): [...] Y únicamente creo que es fundamental que esos jóvenes que han necesitado emigrar para buscar los futuros sepan que aquí se les va a crear las oportunidades necesarias que en otro tiempo se les han negado [...]

Sessió Plenària, Les Corts Valencianes, 22/10/2015

Puede observarse, en este tipo de casos, que la imagen del hablante se pone en juego y se revaloriza, a través de la puesta de relieve de la de otros: aquí, los jóvenes españoles por los que, parece, quiera invertirse y luchar porque puedan volver a trabajar a su país de origen. En estos usos de creo, la imagen de uno se ve afectada por la evaluación que este hace de la de otros.

El tercero y último de los casos en los que se ven envueltas las imágenes es la más frecuente encontrada en el corpus de debate parlamentario $(85,08 \%)$. Se trata de aquellas ocurrencias de creo (que) en las que se realizan actividades de imagen que afectan no solo al hablante colectivo, sino también al oyente colectivo y, en correlación, también a terceros. Todas las imágenes están en juego aquí. Veamos el caso de (6):

(6) Diputado Francisco Javier Hervías Chirosa (grupo parlamentario Ciudadanos): [...] Por tanto, existe un problema y estoy convencido de que no es de la Junta Electoral Central, cuyos funcionarios y trabajadores son un ejemplo — creo yo- en la eficacia de los procesos electorales. No como pasa, por ejemplo, en Venezuela, señores de Podemos, ese país en el que a ustedes tanto les gusta fijarse, ese Gobierno que a ustedes tanto les gusta seguir y del que les gusta aprender y asesorar, que parece que cuando hay un resultado democrático en las urnas no les gusta demasiado [...]

Pleno y Diputación Permanente, Congreso de los Diputados, 20/4/2016 
Se observa aquí que creo, en su manifestación en forma parentética, sirve de comentario a lo propuesto por el diputado de Ciudadanos: que, por un lado, hay un problema en el electorado y que, por otro, este no debe de estar en el funcionariado, del que se dice que trabaja correctamente en España. Lo que se realiza son actos asertivos evaluativos, como vimos previamente, esto es, se introducen juicios de valor, opiniones o puntos de vista del hablante y, como ocurre en el debate parlamentario, no solo de este, sino de todo el grupo parlamentario al que el diputado que toma la palabra representa. En este sentido, estamos viendo que la imagen del enunciador (sea o no colectivo, si bien aquí lo es en casi la totalidad de las situaciones) está siempre involucrada cuando lo que introduce creo en el debate parlamentario es un juicio. Ahora bien, no siempre la imagen de otros se expone y, si lo hace, en muchas ocasiones es para ser denostada y así revalorizar en mayor medida la propia. Lo que ocurre en (6) es que se denuesta la imagen del oyente y el resto de receptores más inmediatos (véase que trata de llevarse la contraria al grupo parlamentario Podemos, poniendo en valor al funcionariado, que ellos critican y en quienes hacen recaer los fallos de las elecciones), para así maximizar la propuesta e imagen propias. Para hacerlo, se trae también a colación, como se lee en el ejemplo, la imagen de terceros (en este caso, la de los funcionarios españoles, a los que se quiere alabar reconociendo su buen hacer). Este es el caso más frecuente en este género y, como vemos, cuando el valor semántico manifestado es el de juicio. Pero veamos con un poco más de detenimiento si existe alguna otra correspondencia con los significados de creo vistos previamente (\$ 4.2) y sus manifestaciones formales ( $(4.1)$.

\section{Tabla 5}

Relación entre actividades de imagen, significados y construcciones formales de creo (que)

\begin{tabular}{|c|c|c|c|c|c|c|c|c|c|c|c|c|}
\hline & & Construcción & \multicolumn{10}{|c|}{ Valor semántico } \\
\hline & & & \multicolumn{3}{|c|}{ conocimiento } & \multicolumn{3}{|c|}{ posibilidad } & \multicolumn{3}{|c|}{ juicio } & $\mathrm{MD}$ \\
\hline & & & \multicolumn{10}{|c|}{ Imagen } \\
\hline & & & $\mathrm{H}$ & $\begin{array}{r}\mathrm{H}+ \\
3 \mathrm{os}\end{array}$ & $\begin{array}{r}\mathrm{H}+\mathrm{O} \\
+3 \mathrm{os}\end{array}$ & $\mathrm{H}$ & $\begin{array}{r}\mathrm{H}+ \\
3 \mathrm{os}\end{array}$ & $\begin{array}{r}\mathrm{H}+\mathrm{O} \\
+3 \mathrm{os}\end{array}$ & $\mathrm{H}$ & $\begin{array}{r}\mathrm{H}+ \\
3 \mathrm{os}\end{array}$ & $\begin{array}{r}\mathrm{H}+\mathrm{O} \\
+3 \mathrm{os}\end{array}$ & $\mathrm{NO}$ \\
\hline \multirow[t]{4}{*}{$\begin{array}{c}\text { creo } \\
\text { (parentéti } \\
\text { co) }\end{array}$} & $\begin{array}{l}\mathrm{c} \\
\mathrm{r} \\
\mathrm{e}\end{array}$ & creo $+\varnothing$ & & & $\begin{array}{c}2 \\
(0,68 \\
\%) \\
\end{array}$ & & & & $\begin{array}{c}1 \\
(0,34 \\
\%) \\
\end{array}$ & & $\begin{array}{c}7 \\
(2,37 \\
\%) \\
\end{array}$ & \\
\hline & o & $\begin{array}{l}\text { creo } \\
\text { infinitivo }\end{array}$ & $\begin{array}{c}1 \\
(0,34 \\
\%)\end{array}$ & & $\begin{array}{c}1 \\
(0,34 \\
\%) \\
\end{array}$ & & & & & & & \\
\hline & & no + creo & & & & & & $\begin{array}{c}1 \\
(0,34 \\
\%)\end{array}$ & & & & \\
\hline & & creo que + & 4 & 2 & 16 & & 2 & 7 & 17 & 10 & 190 & 1 \\
\hline
\end{tabular}




\begin{tabular}{|c|c|c|c|c|c|c|c|c|c|c|c|}
\hline \multirow{7}{*}{$\begin{array}{l}\text { creo } \\
\text { (integrad } \\
\text { o) }\end{array}$} & $\begin{array}{l}\mathrm{c} \\
\mathrm{r}\end{array}$ & $\mathrm{X}$ & $\begin{array}{c}(1,36 \\
\%)\end{array}$ & $\begin{array}{c}(0,68 \\
\%)\end{array}$ & $\begin{array}{c}(5,42 \\
\%)\end{array}$ & $\begin{array}{c}(0,68 \\
\%)\end{array}$ & $\begin{array}{c}(2,37 \\
\%)\end{array}$ & $\begin{array}{c}(5,76 \\
\%)\end{array}$ & $\begin{array}{c}(3,39 \\
\%)\end{array}$ & $\begin{array}{c}(64,41 \\
\%)\end{array}$ & $\begin{array}{c}(0,34 \\
\%)\end{array}$ \\
\hline & $\begin{array}{l}\mathrm{e} \\
\mathrm{o}\end{array}$ & $\begin{array}{l}\text { creo que }+ \\
\text { sí } \\
\varnothing / \text { también }\end{array}$ & $\begin{array}{c}1 \\
(0,34 \\
\%)\end{array}$ & & & & & $\begin{array}{c}2 \\
(0,68 \\
\%)\end{array}$ & & $\begin{array}{c}4 \\
(1,36 \\
\%)\end{array}$ & \\
\hline & $\begin{array}{l}\mathrm{q} \\
\mathrm{u} \\
\mathrm{e}\end{array}$ & $\begin{array}{l}\text { creo que }+ \\
\text { no } \varnothing /+ \text { no } \\
X / \text { tampoco }\end{array}$ & & & $\begin{array}{c}1 \\
(0,34 \\
\%)\end{array}$ & & $\begin{array}{c}1 \\
(0,34 \\
\%)\end{array}$ & & & 6 & \\
\hline & + & $\begin{array}{l}\text { sí } \\
\text { que/tambié } \\
\mathrm{n}+\text { creo } \\
\text { que }\end{array}$ & & & & & & $\begin{array}{c}1 \\
(0,34 \\
\%)\end{array}$ & $\begin{array}{c}1 \\
(0,34 \\
\%)\end{array}$ & $\begin{array}{c}2 \\
(0,68 \\
\%)\end{array}$ & \\
\hline & & $\begin{array}{l}\text { no/tampoc } \\
\text { o }+ \text { creo } \\
\text { que + } \\
\text { (verbo en } \\
\text { subjuntivo) }\end{array}$ & & & & & $\begin{array}{c}12 \\
(4,07 \\
\%)\end{array}$ & & & $\begin{array}{c}1 \\
(0,34 \\
\%)\end{array}$ & \\
\hline & $\begin{array}{l}\mathrm{c} \\
\mathrm{r} \\
\mathrm{e}\end{array}$ & $\begin{array}{ll}\text { creo } & + \\
\text { PVO } & \\
(\text { del OD) }\end{array}$ & & & & & & $\begin{array}{c}1 \\
(0,34 \\
\%)\end{array}$ & & & \\
\hline & $\begin{array}{l}+ \\
\mathrm{P} \\
\mathrm{V} \\
\mathrm{O}\end{array}$ & & & & & & & & & & \\
\hline
\end{tabular}

Se detallan a continuación los resultados que recoge la Tabla 5, que cruza los resultados obtenidos en cuanto a las actividades de imagen que pone en marcha creo (que), sus valores semánticos y sus formas de manifestación. En primer lugar destaca, como veníamos observando de manera cualitativa en la descripción de los ejemplos, que en el debate parlamentario se tiende a expresar un valor de juicio, opinativo o deliberativo (como lo etiqueta la bibliografía internacional) de un modo integrado sintácticamente en la cláusula mediante el transpositor que y que en todos estos casos mueve la imagen tanto del hablante como del oyente colectivos (esto es, el grupo parlamentario receptor en su conjunto), presentes en este género, como de terceros, sujetos externos al acto de comunicación (tanto la colectividad de los ciudadanos españoles como otros receptores externos concretos a los que puede apuntar la enunciación, vid. ej. (6)). En estas circunstancias aparece en el 64,41 $\%$ de los casos en nuestro corpus (con un total de 190 ocurrencias), lo que supone la frecuencia más elevada. En segundo lugar, pero con una frecuencia mucho menor (5,76 \%) a la de los primeros ejemplos comentados, tenemos los casos en los que también se manifiesta un valor semántico de juicio con la variante formal integrada creo que, si bien aquí únicamente se ve afectada la imagen del yo hablante (colectivo), sobre todo para reforzarla. En tercer lugar, en un 5,42\% de las ocasiones, el verbo integrado expresa valores de conocimiento y afecta a las imágenes de todos. Y, con un 4,07 \% de frecuencia encontramos usos de creo integrados en los que se niega el verbo regente (no/tampoco + creo 
que) y este introduce un verbo en modo subjuntivo, con valor semántico de posibilidad y, de nuevo, se ven afectadas todas las posibles imágenes (tanto del hablante y oyente colectivos como de terceros).

Todo ello quiere decir que, si bien los tres valores semánticos comentados de creo modal (si exceptuamos el único caso encontrado de marcador formulativo, que no manifiesta ninguna actividad de este tipo) ponen en juego cuestiones relativas a la imagen, lo hacen en mayor medida los de conocimiento y juicio, pero sobre todo este último, dada su naturaleza evaluativa, como es de esperar. También podemos observar que, cuando aparece este valor, en la mayoría de casos se ven envueltas las imágenes de todos los individuos posibles, aunque también se dan casos de revalorización de la del hablante de manera aislada. Y, por último, que si tomamos las frecuencias más altas de efecto en las imágenes de los interlocutores en relación con los tres valores citados (conocimiento, posibilidad y juicio), vemos que coinciden en ser las correspondientes a la afectación paralela de las imágenes de hablante + oyente + terceros. Esta última observación da cuenta de que en el debate parlamentario, de uno u otro modo, se ponen en juego elementos externos al momento de la enunciación. Por esta razón, los efectos de esta enunciación también trasgreden sus fronteras. Esto es, el debate parlamentario es un género cuyo alcance perlocutivo está no solo dentro sino también fuera del propio texto y de su bic et nunc. Asimismo, que predominen las afectaciones de imagen vistas y con los valores comentados, sobre todo en el caso del juicio, nos lleva a confirmar la relación entre estos aspectos y su proceder pragmático, como más tarde veremos ( $(4.5)$.

\subsection{Otros aspectos relevantes en las manifestaciones de creo (que)}

Paralelo a lo expuesto en $\ 4.3$, existen otros elementos que afectan a la puesta en marcha de distintos tipos de actividades de imagen en el discurso y que, estos sí, se dan en el momento mismo de la enunciación. Estos elementos extralingüísticos no deben desdeñarse si tomamos un enfoque sociopragmático de análisis de la imagen y del discurso (Bravo 2009). Nos referimos a cuestiones como la presencia de la ironía, la metaforización, los aplausos que muchas veces acompañan a lo dicho por los diputados o las risas o murmullos que también suelen aparecer junto a sus intervenciones, en una u otra dirección. Si bien no se trata de observaciones que podamos cuantificar, si vale la pena dedicarles un breve espacio, pues afectan a la configuración de lo dicho y, en última instancia, al desarrollo funcional de las formas. 
Hemos observado que, de manera independiente de la forma y el valor semántico manifestado por creo (que), suele aparecer la ironía como refuerzo de la imagen del yo en lo dicho o como ataque indirecto, pero no por ello suavizado, sino más bien como resorte para hacer de este una crítica más fuerte al otro y, en todos estos casos, se ve implicada tanto la imagen del yo, como la del otro y de terceros. Esto es, se ha detectado la aparición de la ironía en muchos de los casos de los del tipo de los más frecuentes ya descritos. Son ejemplos como el que sigue:

(7) Diputado Fernando Pastor Llorens (grupo parlamentario Popular): [...] Dice usted que su conseller ... (Remors) A mí no me molesta que hablen, no soy como el señor Mata, a mí no me molesta que hablen ustedes. Le quiero decir que ustedes dicen que el conseller, me acaba de decir, se reúne con todos los sectores productivos de la comunidad, pero no acaba de decir lo que les dice. Porque yo creo que será muy duro para el señor Climent sentarse, y para el señor Puig también, sentarse, mirarles a la cara a los empresarios valencianos, a los agricultores valencianos y decirles, «mira, nosotros en las Cortes votamos dos tercios del pacto que me sustenta que no - eso lo diría Ximo Puig, el presidente Puig- dos tercios del pacto Podemos y Compromís dicen que no a que vosotros podáis tener facilidades para exportar a Estados Unidos» [...]

Sessió Plenària, Les Corts Valencianes, 22/10/2015

De acuerdo con Ruiz Gurillo (2014), la ironía puede entenderse como una implicatura conversacional particularizada con la que se viola la máxima de cualidad de Grice. En este sentido, puede ser incluso interpretada en algunos casos como un fingimiento pretendido (Grice, Clark y Gerrig 1984). Es lo que puede observarse en (7), en que el diputado Pastor Llorens dice que el grupo Socialista debe de considerar duro enfrentarse a los empresarios y agricultores valencianos para confesarles que fue gran parte de sus apoyos la que votó no permitirles exportar productos a los Estados Unidos. El diputado y su partido piensan que aquellos no pueden realizar tales afirmaciones, pues de este modo los representantes de dicho partido político actuarían contra su propia imagen.

Fijémonos, además, en que al principio del fragmento se dan una serie de murmullos (Remors) por parte de los diputados del grupo de la oposición, lo que afecta al parlamento de Pastor y lo obliga a defenderse alegando que no se molesta por aquello. Tras 
ello, expone su punto de vista y trata de argumentarlo de la manera más fuerte posible, pues comienza su intervención no siendo escuchado por el resto o, si se prefiere, sin el crédito de quienes lo escuchan, como si de una deslegitimización se tratara (Infante y Flores 2015), algo que lo obliga a fortalecer en la medida de lo posible aquello que asevera. Esto ocurre con frecuencia en el debate parlamentario, pues se manifiesta un grado elevado de evaluación o afectividad, si se entiende esta como un tipo de evaluación o de actitud del hablante ante lo dicho (Bolívar 2015), que ha de venir en muchos casos reforzada y puede encontrar en la ironía un recurso argumentativo eficaz para su exposición.

Ocurrirá algo parecido cuando aparezcan las risas, pues en muchas ocasiones tratan de derribar lo enunciado por el adversario ${ }^{10} \mathrm{o}$, contrariamente, cuando se den los aplausos, que se coorientan con el refuerzo de lo dicho, tan necesario en este género discursivo. Son elementos que de uno u otro modo provocan un efecto social (Hernández Flores 2013) que lo lingüístico ayuda a regular.

\subsection{Las categorías pragmáticas de creo (que): las funciones de intensificación}

El análisis da cuenta de que creo (que) puede expresar una gran diversidad de funciones pragmáticas en el discurso, si bien en este género predominan las de intensificación, de acuerdo con los resultados de algunos estudios previos (Fuentes Rodríguez 2010, 2013; Brenes Peña 2015; Cuenca 2015). De los 295 casos de creo (que) modal encontrados en el corpus, 1 de ellos presenta una función de marcación (0,34 \%), 4 usos de creo (que) (1,36 \%) sirven para introducir un juicio, si bien la ilocución de este ni se minimiza ni se maximiza, 78 casos presentan atenuación (26,44\%), y 212 (71,86\%), intensificación.

Como se ha visto, la intensificación es la categoría reina de entre las funciones pragmáticas posibles de creo (que) en el debate parlamentario. Aparece en el 71,86 \% de los casos, si bien no es la única que puede reconocerse en sus usos ni debe asociarse de manera directa ni al género textual ni a un solo valor semántico de la forma verbal objeto de estudio, aunque sí que puedan observarse algunas condiciones discursivas que desde uno y otro lado favorecen su aparición.

\footnotetext{
$10 \mathrm{La}$ asiduidad con la que este tipo de recursos aparece en el discurso debe ser evaluada en mayor profundidad para poder determinar hasta qué punto constituyen descalificaciones continuadas que, junto a las verbales, pueden llegar a ser descorteses (González Sanz 2017).
} 
Se ha visto a lo largo del trabajo que la idiosincrasia del debate parlamentario en España, si bien también ocurre lo mismo en otros ámbitos, favorece la aparición de las evaluaciones y afectaciones que, en muchos casos, vienen a ser expresadas mediante verbos de actitud proposicional, que introducen actos de habla asertivos. Ahora bien, no quiere decir esto que en este tipo de género todo lo que nos encontremos sean juicios, pues en muchas ocasiones también hemos reconocido la aparición de creo junto a enunciados descriptivos de conocimiento o epistémicos. Por otro lado, se ha visto cómo sí se exige en este género que responda a fines argumentativos pues, en la mayor parte de los casos, deberá reforzar los puntos de vista defendidos por cada uno de los hablantes que representan la voz de un grupo parlamentario, incluso por oposición a otro/-s. Lo que hace que no solo se trate de maximizar la propia imagen, sino de hacerlo en detrimento y/o superponiéndose a otra/-s. Teniendo estas observaciones en cuenta y los aspectos analizados hasta aquí -respecto a la forma, significado y cuestiones de imagen en los usos de creo (que)-, vamos a observar qué es lo que ocurre con la forma objeto de estudio en el plano pragmático, cuando manifiesta intensificación. La siguiente tabla es un resumen de las características analizadas en nuestra investigación de corpus, únicamente para aquellos casos en los que creo (que) es intensificador:

\section{Tabla 6}

Resumen de características cruzadas de los 212 casos de creo (que) intensificador en el corpus

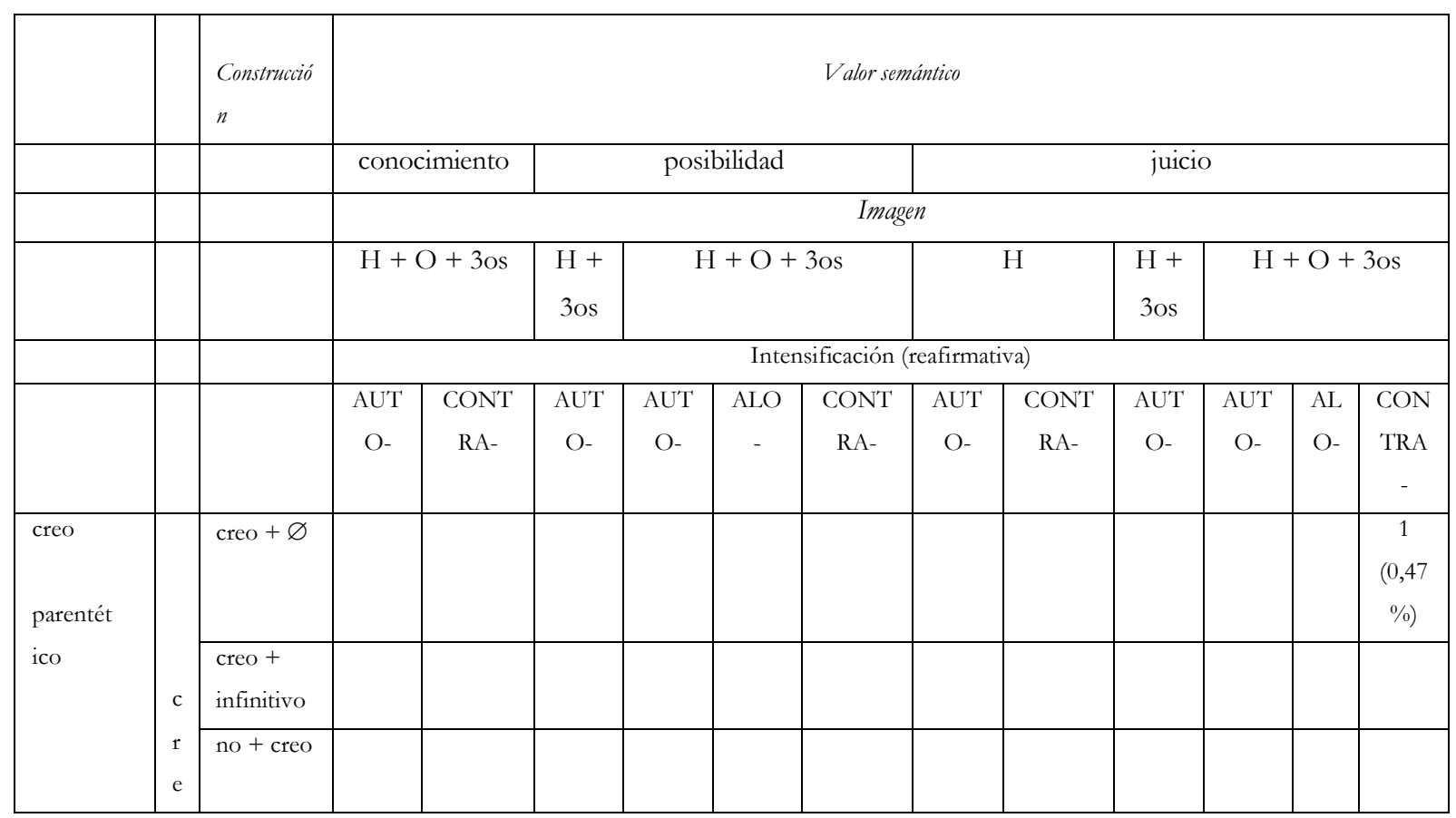




\begin{tabular}{|c|c|c|c|c|c|c|c|c|c|c|c|c|c|c|}
\hline & o & & & & & & & & & & & & & \\
\hline & & creo que & 1 & 3 & 1 & 2 & 1 & 2 & 13 & 1 & 7 & 95 & 11 & 58 \\
\hline & & $+x$ & $(0,47$ & $(1,42$ & $(0,4$ & $(0,94$ & $(0,47$ & $(0,94$ & $(6,13$ & $(0,47$ & $(3,3$ & $(44,8$ & $(5$, & $(27,3$ \\
\hline & & & $\%)$ & $\%)$ & $7 \%)$ & $\%)$ & $\%)$ & $\%)$ & $\%)$ & $\%)$ & $\%)$ & $1 \%)$ & 19 & $6 \%)$ \\
\hline & & & & & & & & & & & & & $\%)$ & \\
\hline & & creo que & & & & & & & 1 & & & 1 & 1 & 1 \\
\hline & & & & & & & & & $(0,47$ & & & $(0,47$ & $(0$, & $(0,47$ \\
\hline & & $\varnothing /$ tambié & & & & & & & $\%)$ & & & $\%)$ & 41 & $\%)$ \\
\hline & & $\mathrm{n}$ & & & & & & & & & & & $\%)$ & \\
\hline & c & creo que & & 1 & & & & & & & & & 1 & 1 \\
\hline & r & + no & & $(0,47$ & & & & & & & & & $(0$, & $(0,47$ \\
\hline & e & $\varnothing /+$ no & & $\%)$ & & & & & & & & & 47 & $\%)$ \\
\hline creo & o & $\mathrm{X} /$ tampo & & & & & & & & & & & $\%)$ & \\
\hline & & со & & & & & & & & & & & & \\
\hline & & sí & & & & & & & 1 & & & 1 & & \\
\hline & $\mathrm{q}$ & que/tamb & & & & & & & $(0,47$ & & & $(0,47$ & & \\
\hline & u & ién + & & & & & & & $\%)$ & & & $\%)$ & & \\
\hline integrado & & creo que & & & & & & & & & & & & \\
\hline integrado & & no/tamp & & & & & & & & & & 2 & & 4 \\
\hline & & $\mathrm{oco}+$ & & & & & & & & & & $(0,94$ & & $(1,89$ \\
\hline & & creo que & & & & & & & & & & $\%)$ & & $\%)$ \\
\hline & + & + (verbo & & & & & & & & & & & & \\
\hline & & en modo & & & & & & & & & & & & \\
\hline & & o) & & & & & & & & & & & & \\
\hline & c & $\begin{array}{lc}\text { creo }+ \\
\end{array}$ & & & & & & & 1 & & & & & \\
\hline & $\mathrm{r}$ & PVO & & & & & & & $(0,47$ & & & & & \\
\hline & e & $(\mathrm{del} O \mathrm{OD})$ & & & & & & & $\%)$ & & & & & \\
\hline & o & & & & & & & & & & & & & \\
\hline & + & & & & & & & & & & & & & \\
\hline & P & & & & & & & & & & & & & \\
\hline & $\begin{array}{l}\mathrm{V} \\
\mathrm{O}\end{array}$ & & & & & & & & & & & & & \\
\hline & & & & & & & & & & & & & & \\
\hline
\end{tabular}

En la tabla superior se observa cómo se reparten las funciones de intensificación entre los 212 casos de creo (que). Este resumen nos permite ver cuáles son las tendencias de desarrollo de este fenómeno. Pueden realizarse tres observaciones al respecto.

Primeramente, vemos en la Tabla 6 que el fenómeno de la intensificación predomina sobre todo con una función auto-reafirmartiva, de acuerdo con la propuesta de funciones de Briz (2017) para dicha categoría. Presenta, con estas características, los 
porcentajes más altos de aparición en la manifestación de casi todos los significados de creo (que) y con casi la totalidad de sus construcciones formales, a excepción de únicamente dos casos de creo que y no/tampoco + creo que + (verbo en modo subjuntivo) en los que el valor contrareafirmativo de la intensificación supera al de sus mismas manifestaciones con valor autoreafirmativo.

También se detecta el predominio de la intensificación en los usos de creo (que) como introductor de juicios u opiniones. Todos los casos de intensificación con estas características presentan las frecuencias absolutas más elevadas de la tabla. Y, entre ellas, ocupa el primer lugar la función auto-reafirmativa y, el segundo, la contra-reafirmativa (siempre en las segundas posiciones de frecuencia en el debate).

Finalmente, los datos nos proporcionan también información acerca del comportamiento de la intensificación de creo (que) en cuanto a las actividades de imagen. El estudio confirma que la intensificación siempre viene ligada a estas -así como también se reconoce en otros estudios para el caso de la atenuación (Albelda 2016 y en prensa) - y, más específicamente, que esta predomina, se dé junto al valor semántico que se dé, cuando las imágenes que se ponen en juego no son solamente las del hablante y el oyente (ambos colectivos), sino cuando también se involucran la/-s de terceros, ajenos al acto mismo de comunicación.

La propuesta de funciones de intensificación defendida por Briz (2017) establece tres tipos de refuerzo a partir del foco de lo realzado: a) si este se pone en la voz del propio hablante, intensificación auto-reafirmativa; b) si se pone en la voz del otro u otros, receptores, intensificación alo-reafirmativa; c) si lo que se pone de relieve es la confrontación entre ambas voces, la del hablante y la de los receptores, intensificación contra-reafirmativa.

El primero de estos tipos de intensificación (auto-reafirmativa) queda claro en ejemplos como el visto en (4), retomado aquí como (4'):

(4’) Expresidente del Gobierno Mariano Rajoy Brey (grupo parlamentario Popular): [...] Creo que el gran objetivo político de esta legislatura era superar la crisis económica, hemos evitado un rescate, hemos evitado la quiebra de nuestro país, hemos superado una crisis de deuda soberana, una crisis financiera y el gran objetivo ahora es crecer y crear empleo [...]

Pleno y Diputación Permanente, Congreso de los Diputados, 7/5/2014 
Recuérdese la autoalabanza a las acciones de gobierno puestas en marcha por el Partido Popular en este fragmento -llevada a cabo mediante la enumeración de objetivos cumplidos y la repetición- y que el expresidente Mariano Rajoy defendía como eficaces en la extracción del país de la crisis económica en la que estaba sumido. En estos casos se confirma la propuesta realizada por Briz (2017).

El segundo de los tipos, el alo-reafirmativo, lo representa el siguiente ejemplo (8):

(8) Diputada Pilar Teresa Sarrión Ponce (grupo parlamentario Socialista): [...] Gracias a los docentes, a los expertos en educación, a los representantes de la administración, a Escola Valenciana, a las AMPA, a los sindicatos y a las asociaciones de estudiantes que han pasado por la comisión. Creo que sin sus aportaciones, todo lo que ellos nos han hecho ver y nos han abierto los ojos, este informe no hubiese resultado como al final hoy se presenta y se va a aprobar [...] Sessió Plenària, Les Corts Valencianes, 26/3/2015

En este caso, se refuerza la imagen del otro, se pone en valor a terceros (docentes y demás personal de educación de la Comunidad Valenciana), lo que, a la vez, deja la imagen del hablante en buen lugar. Aquí se opta por intensificar las acciones de otros, aunque no estén presentes en el acto comunicativo, lo que a la vez supone un refuerzo de lo dicho y de la vOz del yo. Es un modo de manifestar alianza con los otros, expresada mediante incluso una hipérbole (pues se llega a afirmar que, si no hubiese sido por la acción de las personas citadas, el nuevo decreto de educación no se podría haber materializado) y reesponsabilización del otro de los méritos propios, si bien no deja de ser una táctica de refuerzo del propio yo.

Por el contrario, en el tercero de los casos propuesto por Briz (2017), lo que se intensifica es la confrontación misma entre el hablante y el oyente, o terceros. Véase (9):

(9) Exministro Alberto Ruiz-Gallardón (grupo parlamentario Popular): Señor Baldoví, usted dice que cumple con su obligación, pero déjeme que le diga que usted tiene una responsabilidad superior como consecuencia de estar sentado en el escaño donde acaba de tomar asiento, como consecuencia de haber sido democráticamente elegido por los ciudadanos, como consecuencia del juramento que hizo de acatar la 
Constitución española. Como consecuencia de todo ello no creo que usted —se lo digo con toda sinceridad - esté contribuyendo a esa confianza que en usted se depositó ni tampoco al compromiso que adquirió de defender nuestras instituciones.

Pleno y Diputación Permanente, Congreso de los Diputados, 25/6/2014

En este ejemplo se refuerza el desacuerdo y la denostación del otro. Se focaliza la crítica a las acciones de Baldoví y se pone así, de nuevo, en valor la voz del propio hablante, que manifiesta decir aquello de manera sincera y con cierta elaboración argumentativa. El exministro Ruiz-Gallardón poya estos sus argumentos en lo que considera son pruebas personales suficientes para concluir que su interlocutor no está trabajando de acuerdo con la confianza y responsabilidad que se le brindó. Se trata, por tanto, de una manifestación de un punto de vista que se contrapone al del otro, lo rebate.

Lo que comprobamos, con estos tres tipos de usos intensificadores de creo (que) es que pueden efectivamente reconocerse diferentes funciones de esta, si bien en última instancia todas parecen enfocarse hacia la revalorización del yo, incluso cuando lo hacen estratégicamente reforzando la imagen de otro o denostándola. El mecanismo a través del cual se llega a manifestar la intensificación es distinto en cada caso, a pesar de que se dispone argumentativamente de manera tal que el resultado ofrecido viene a ser semejante: una auto-intensificación, función que subyace a cualquiera de las acciones vistas y que viene a confirmar que en el debate parlamentario, como también ocurre en otros géneros orales en español (Douglas, Soler y Vuoto 2018), las actividades primordiales que vertebran la argumentación son de autoimagen.

\section{Conclusiones}

Este trabajo ha tratado de ser una aproximación descriptiva al funcionamiento pragmático intensificador de la forma verbal doxástica creo (que) a partir de la observación de distintos aspectos formales, significativos y discursivos en sus manifestaciones en un corpus de debate parlamentario en España, en los últimos cuatro años (2014-2017). El análisis ha desvelado que no se pueden establecer correlaciones directas entre algunos de estos aspectos observados en creo (que) y su función pragmática, si bien sí pueden realizarse algunas generalizaciones por lo que a la irrupción de la intensificación se refiere. Se ha podido ver cómo este fenómeno viene ligado, en gran medida, a significados de juicio 
introducidos por el verbo (en la mayoría de los casos a través de una construcción integrada sintácticamente en la cláusula) y que con gran frecuencia en ellos se activan las imágenes, no solo del hablante y del oyente (y de los partidos que ellos representan), sino también de terceros ajenos al momento de la enunciación. En estos casos, además, se ha comprobado que la función principal intensificadora es la auto-reafirmativa, y que incluso en las manifestaciones de alo- y contra-reafirmación, el fin que se persigue es el refuerzo del yo, al menos en el corpus de debate parlamentario español analizado. Por consiguiente, creo (que) se comporta en el género cotejado como una estrategia argumentativa eficaz y altamente subjetiva, que es capaz de embaucar retóricamente al otro para someterlo al yo.

El análisis confirma, además, que la intensificación es la categoría pragmática más frecuentemente expresada, con diferentes funciones, en los usos de creo (que) en el debate parlamentario español, como apuntaban ya algunos estudios. Si bien, este resultado contradice las generalidades anotadas en muchos trabajos sobre atenuación en distintos tipo de discurso, que clasifican esta forma verbal doxástica como ejemplo paradigmático de este último fenómeno pragmático.

En futuros trabajos, convendrá ampliar el corpus de análisis, así como extender el estudio a otros tipos de discurso político y a otros géneros interactivos orales, con el fin de poder realizar observaciones más amplias por lo que al comportamiento significativofuncional de creo (que) se refiere -tanto en su variedad genérica como también diafásica-.

\section{Referencias}

Albelda, M. (2007): La intensificación como categoría pragmática: revisión y propuesta. Frankfurt am Main: Peter Lang.

Albelda, M. (2016). Sobre la incidencia de la imagen en la atenuación pragmática. Revista Internacional de Lingüistica Iberoamericana 14.1 (27), 19-32.

Albelda, M. (en prensa). La variación genérico-discursiva de la atenuación como resultado de la variación de la imagen. Spanish in Context.

Albelda, M., A. Briz, A. Cestero, D. Kotwica y C. Villalba (2014). Ficha metodológica para el análisis pragmático de la atenuación en corpus discursivos del español. ES.POR.ATENUACIÓN. Oralia 17, 1-44.

Andersen, H. L. (1997). Propositions parenthétiques et subordination en français parlé. Thèse de doctorat. Copenhague : Université de Copenhague.

Benveniste, É. (1958). De la subjectivité dans le langage. Journal de Psychologie 55, 257-265.

Berlin, L. N. (2008). I think, therefore...: commitment in political testimony. Journal of Language and Social Psychology 27 (4), 372-383.

Berlin, L. N. (2011). Redundancy and markers of belief in the discourse of political hearings. Language Sciences 33 (2), 268-279. 
Blanche-Benveniste, C. (1989). Constructions verbales 'en incise' et rection faible des verbes. Recherches sur le Français Parlé 9, 53-73.

Blanche-Benveniste, C. y D. Willems (2007). Un nouveau regard sur les verbes faibles. Bulletin de la Société de Linguistique de Paris CII (1), 217-254.

Bolívar, A. (2015). La intensificación como señal de cambio en los géneros políticos. En Bravo, D. y Bernal, M. (Eds.) Perspectivas sociopragmáticas y socioculturales del análisis del discurso. Buenos Aires: Dunken, 97-137.

Bravo, D. (2009). Pragmática, sociopragmática y pragmática sociocultural del discurso de la cortesía: Una introducción. En Bravo, D., Hernández-Flores, N. y Cordisco, A. (Eds.) Aportes pragmáticos, sociopragmáticos y socioculturales a los estudios de la cortesía en español. Buenos Aires: Programa EDICE-Dunken, 31-68.

Brenes Peña, E. (2015). La intensificación de la aserción en el Parlamento andaluz. Análisis pragmalingüístico de los verbos de opinión. Cultura, Lenguaje y Representación 14, 931.

Briz, A. (2017). Una propuesta funcional para el análisis de la estrategia pragmática intensificadora en la conversación coloquial. En Albelda, M. y Mihatsch, W. (Eds.). Atenuación e intensificación en géneros discursivos. Madrid: Iberoamericana Vervuert. Linguîstica Iberoamericana 65, 43-67.

Buceta, O. (2014). Construcciones del verbo 'creer'. Factótum 12, 74-90.

Caffi, C. (1999). On mitigation. Journal of Pragmatics 3, 881-909.

Caffi, C. (2004). Mitigation: a pragmatic approach. Oxford: Elsevier.

Cuenca, M. J. (2015). Evidentiality (and epistemicity) in Catalan parliamentary debate. eHumanista/IVTTRA 8, 362-382.

De Cock, B. (2014): Profiling discourse participants. Forms and functions in Spanish conversation and debates. Amsterdam-Philadelphia: John Benjamins.

De Saeger, B. (2007). Evidencialidad y modalidad epistémica en los verbos de actitud proposicional en español. Interlingüística 17, 268-277.

Douglas, S., Soler, M. A. y Vuoto, J. (2018). La atenuación en conversaciones coloquiales argentinas y españolas: un estudio contrastivo. Nuevas aportaciones sobre la atenuación pragmática. Formas, funciones y variación lingüistica. RILCE 34 (3), 1280-1312.

Fetzer, A. (2014). I think, I mean and I believe in political discourse. Collocates, functions and distribution. Functions of Language 21 (1), 67-94.

Fetzer, A. y M. Johansson (2010). Cognitive verbs in context. A contrastive analysis of English and French argumentative discourse. International Journal of Corpus Linguistics 15 (2), 240-266.

Fraser, B. (1975). Hedged performatives. En Cole, P. y J. Morgan (Eds.) Syntax and semantics 3, Speech acts. New York: Academic Press, 187-210.

Fraser, B. (1980): Conversational mitigation. Journal of Pragmatics 4, 341-350.

Fraser, B. (2010). Hedging in political discourse. The Bush 2007 press conferences. En Okulska, Urszula, P. (Eds.) Perspectives in Politics and Discourse, 201-214.

Frege, G. (1892). Über Sinn und Bedeutung. Zeitschrift für Philosophie und philosophische Kritik 10, 25-50.

Fuentes Rodríguez, C. (2010). La aserción parlamentaria: de la modalidad al metadiscurso, Oralia 13, 97-125.

Fuentes Rodríguez, C. (2013). Parentéticos, hedging y sintaxis del enunciado. CLAC. Círculo de Lingüística Aplicada a la Comunicación 55, 61-94.

Fuentes Rodríguez, C. (2015). La intensificación como estrategia de refuerzo argumentativo en el discurso de parlamentarios y parlamentarias". En Bravo, D. y Bernal. M. 
(Eds.) Perspectivas sociopragmáticas y socioculturales del análisis del discurso. Buenos Aires: Dunken, 183-226.

Fuentes Rodríguez, C. (2016). Atenuación e intensificación estratégicas. En Fuentes Rodríguez, C. (Ed.) Estrategias argumentativas y discurso politico. Madrid: Arco/Libros, 163-222.

González Ruiz, R. (2014). Sintaxis, semántica y discurso: algunas reflexiones en torno a los verbos de opinión (con especial referencia al español). En Pérez Salazar, C. e I. Olza Moreno (Eds.) Del discurso de los medios de comunicación a la lingüistica del discurso. Estudios en honor de la profesora María Victoria Romero. Berlín: Frank \& Timme, 245278.

González Ruiz, R. (2015). Los verbos de opinión entre los verbos parentéticos y los verbos de rección débil: aspectos sintácticos y semántico-pragmáticos. CLAC. Círculo de Lingüistica Aplicada a la Comunicación 62, 148-173.

Grice, P., Clark, H. y Gerrig, J. (1984). On the Pretense Theory of Irony. Journal of Experimental Psychology 113 (1), 121-126.

González Sanz, M. (2017). Tertulia e ideología. La mediatización del pensamiento politico. Bern: Peter Lang.

Hennemann, A. (2012). The epistemic and evidential use of Spanish modal adverbs and verbs of cognitive attitude. Folia Linguistica 46 (1), 133-170.

Hennemann, A. (2016). A cognitive-constructionist approach to Spanish creo $\varnothing$ and creo yo '[] think'. Folia Linguistica 50 (2), 449-474.

Hernández Flores, N. (2013). Actividad de imagen: caracterización y tipología en la interacción comunicativa. Pragmática Sociocultural 1 (2), 175-198.

Holmes, J. (1984). Modifying illocutionary force. Journal of Pragmatics 8 (3), 345-365.

Hooper, J. B. (1975). On assertive predicates. En Kimball, J. (Ed.) Syntax and Semantics. Nueva York: Academic Press IV, 91-124.

Infante, M. y Flores, M. E. (2015). Imagen y (des)cortesía en el discurso de los políticos mexicanos. En Bravo, D. y Bernal, M. (Eds.) Perspectivas sociopragmáticas y socioculturales del análisis del discurso. Buenos Aires: Dunken, 265-303.

Jaszczolt, K. M. (1997). The 'default de re' principle for the interpretation of belief utterances. Journal of Pragmatics 28 (3), 5-336.

Johansson, M. (2008). Presentation of the Political Self. Commitment in Electoral Media Dialogue. Journal of Language and Social Psychology 27 (4), 397-408.

Kaltenböck, G. (2010). Pragmatic functions of parenthetical I think. En Kaltenböck, G., Mihatsch, W. y Schneider, S. (Eds.) New approaches to hedging. Bingley: Emerald, 243270.

Kimball, J. P . (Ed.) (1975). Syntax and Semantics IV. New York: Academic Press.

Lakoff, G. (1972). Hedges: a study in meaning criteria and the logic of fuzzy concepts. Journal of Philosophical Logics 2, 458-508.

Leech, G. N. (1980). Explorations in Semantics and Pragmatics. Amsterdam: John Benjamins.

Lysvåg, P. (1975). Verbs of hedging. En Kymball, J. (Ed) Syntax and Semantics IV, 125-154.

Mindt, I. (2003). Is 'I think' a discourse marker? En Mengel, E. y Schmid, H. J. (Eds.) Proceedings Anglistentag. Bayreuth, Trier: WVT, 473-483.

Miyajima, A. (2000). Aparición del pronombre sujeto en español y semántica del verbo. Sophia Lingüistica 47 (46), 73-88.

Mullan, K. (2010). Expressing opinions in French and Australian English discourse: a semantic and interactional analysis. Amsterdam/Philadelphia: John Benjamins.

Nuyts, J. (2001). Subjectivity as an evidential dimension in epistemic modal expressions. Journal of Pragmatics 33, 383-400. 
Pano, A. (2017). Opinión y atenuación en los comentarios de la prensa digital española. CLAC. Círculo de Linguïstica Aplicada a la Comunicación 73, 103-124.

Persson, G. (1993). Think in a panchronic perspective. Studiu Neophilologica 63, 3-18.

Posio, P. (2013). Subject expression in grammaticalizing constructions: The case of creo and acho 'I think' in Spanish and Portuguese. Journal of Pragmatics 63, 5-18.

Rabab'ah, G. y Abu Rumman, R. (2015). Hedging in Political Discourse: Evidence from the Speeches of King Abdullah II of Jordan. Prague Journal of English Studies 4 (1), 157-185.

Ruiz Gurillo, L. (2014). Infiriendo el humor. Un modelo de análisis para el español. CLAC. Círculo de Lingüistica Aplicada a la Comunicación 59, 148-162.

Russell, B. (1918). The Philosophy of Logical Atomism. The Monist, 177-281.

Šandová, J. (2015). On the Use of Cognitive Verbs in Political Interviews. Brno Studies in English 41 (1), 41-59.

Schneider, S. (1999). Il congiuntivo tra modalità e subordinazione. Uno studio sullitaliano parlato. Roma: Carocci.

Schneider, S. (2007). Reduced Parenthetical Clauses as Mitigators. Amsterdam/Philadelphia: John Benjamins.

Schneider, S. (2010). Parenthetical hedged performatives. En Kaltenböck, G., Mihatsch, W. y Schneider, S. (eds.) New approaches to hedging. Bingley: Emerald, 267-287.

Schneider, S., Glikman, J. y Avanzi, M. (Eds.) (2015). Parenthetical verbs. Berlin/New York: De Gruyter Mouton.

Simon-Vandenbergen, A. M. (2000). The functions of $I$ think in political discourse. International Journal of Applied Linguistics 10 (1), 41-63.

Soler, M. A. (2016). La función atenuante en los verbos doxásticos del español. Revista Internacional de Lingüistica Iberoamericana XIV-1 (27), 75-90.

Soler, M. A. (2018). Fingimientos y atenuación en el uso de creo. Nuevas aportaciones sobre la atenuación pragmática. Formas, funciones y variación lingüistica. RILCE 34 (3), 1104-1128.

Torres-Martínez, S. (2017). Working out multiword verbs within an Applied Cognitive Construction Grammar Framework. EuJAL 5 (1), 55-86.

Travis, C. E. y Torres Cacoullos R. (2012). What do subject pronouns do in discourse? Cognitive, mechanical and constructional factors in variation. Cognitive Linguistics 23 (4), 711-748.

Travis, C. E. y Torres Cacoullos, R. (2014). Stress on I. Debunking unitary contrast accounts. Studies in Language 38 (2), 360-392.

Venier, F. (1991). La modalizzarione assertiva. Avverbi modali e verbi parentetici. Milano: Franco Angeli.

Wichmann, A. (2001). Spoken parentheticals. En Aijmer, K. (Ed.). A Wealth of English (Studies in honour of Göran Kjellmer). Göteborg: Acta Universitatis Gothoburgensis, 177-193.

Wierzbicka, A. (2006). English: Meaning and Culture. New York: Oxford University Press.

\section{Corpus consultados}

Congreso de los Diputados. Disponible en http://www.congreso.es/portal/page/portal/Congreso/Congreso/Publicaciones/DiaSes Les Corts Valencianes. Disponible en http://www.cortsvalencianes.es/cs/Satellite/Layout/Page/1260974740177/Publicaciones. $\underline{\mathrm{html}}$ lang $=\mathrm{ca} \mathrm{VA}$ 
M. Amparo Soler Bonafont es licenciada en Filología Hispánica, investigadora del Grupo Val.Es.Co. y miembro del equipo de trabajo del proyecto Es.Vag.Atenuación: La atenuación pragmática en su variación genérica: géneros discursivos escritos y orales en el español de España y América (ref. FFI2016-75249-P, MINECO, Gobierno de España). Actualmente es becaria FPI del Ministerio de Economía y Empresa en la Universitat de València. Sus temas de investigación son el dominio semántico de la modalidad epistémica, los marcadores discursivos y los verbos de opinión, y la atenuación como categoría pragmática.

M. Amparo Soler Bonafont has a degree in Hispanic Philology, she is a researcher of the Grupo Val.Es.Co. and a member of the work group in Es.Vag.Atenuación Project, called La atenuación pragmática en su variación genérica: géneros discursivos escritos y orales en el español de España y América (ref. FFI2016-75249-P, MINECO, Gobierno de España). Nowadays she has a FPI grant from the Ministerio de Economía y Empresa in Universitat de València. Her research topics are the semantic domain of epistemicity, discourse markers and propositional attitude verbs, and attenuation as a pragmatic category. 